\title{
下肢部の局所的圧迫が皮膚温および筋電位に及ぼす影響について
}

\author{
綿貫 茂喜, 三平 和雄 \\ 大阪市立大学 生活科学部
}

\section{The Effect of Partial Pressure on Lower Extremity upon Skin Temperature and Electromyogram}

\author{
Shigeki Watanuki, and Kazuo Mrhira \\ Faculty of Science of Living, Osaka City University. \\ Sugimoto-cho, Sumiyoshi-ku, Osaka-city, 558 Japan
}

The purpose of this study was to investigate the effect of partial pressure on the lower extremity upon the skin temperature (Ts) and the electromyogram (EMG).

In the measurement of $T s$, the upper region of the ankle or the lower region of the thigh in the right extremity was pressured with a cuff $(7 \mathrm{~cm}$ in width) inflated at 40 or $80 \mathrm{mmHg}$ for $60 \mathrm{~min}$. The experiment was also conducted under normal conditions. Ts of the dorsal side of the feet, the lower part of the pressure region, the upper part of pressure region and a symmetrical region of pressure in the left extremity were measured while the subject was sitting. For the measurement of surface EMG, the gastrocnemius, the tibialis anterior, the vastus medialis and the vastus lateralis were measured with the knee in a bending posture for $9 \mathrm{~min}$. Prior to exercise, the angle of ankle joint was adjusted to get the level of contraction corresponding to about $25 \%$ of the maximum voluntary contractions (MVC) of the tibialis anterior. Pressure was then applied to the leg or the thigh by a cuff inflated to 20,40,60 or $80 \mathrm{mmHg}$ during $2.7 \mathrm{~min}$ of the work. The experiment was also conducted under normal condition. The results were as follows. Generally Ts was decreased by the pressure. However, there was no significant difference in the degree of decrease between pressures. And furthermore, the Ts of dorsal side of right foot was the same as that of left foot regardless of the pressurized region. The $T$ s of a symmetrical region decreased as compared with that of the pressurized region regardless of the pressurized region. It was inferred that the decrease of the Ts might have resulted from the action of a pressure reflex.

In a non-active muscle (gastrocnemius), the change of \%MIE (Maximum Integrated EMG) by the pressure ( $\triangle \mathrm{MIE}$ ) was not shown regardless of the pressure region. In an active muscle (tibialis anterior), $\triangle \% \mathrm{MIE}$ was not shown while the thigh was pressured, however, in the case of where the leg was pressured at $80 \mathrm{mmHg}$, the $\triangle \% \mathrm{MIE}$ decreased. It seemed that application of high pressure to a working muscle improved its work efficency. However, after release of the $80 \mathrm{mmHg}$ pressure the increase of \%MIE created by the release of pressure until the end of work was large as compared with normal condition. It was inferred that application of the pressure to the active muscle might have produced the increment of muscle load.

Key word : Partial pressure, Skin temperature, Electromyogram 


\section{1.はじめに}

下肢部の压迫は極度に第屈なズボンや与王服着用時 に発生する。前報（綿貫と三平，1986）では下肢部与 正時の心理特性の変化について検討したが，本報では 王迫が生理機能の1つである皮膚温および筋電位に及 ぼす影響を検討した，珐迫による皮膚温の変化につい ては過去にも報告されているものがあるが（大野と田 中, 1974), 下肢部の細か心部位間の皮膚温の相違につ いては検討されていないまた，王迫が筋作業に及注 す影響は阻血状態では検討されているが(Humphreys and Lind. 1963, Magora et al. 1980)，下肢部を拘束し てはいても衣服による拘束の影響のように阻血を生じ ない程度の王迫が筋作業にどのような影響を与えるか については未だ明らかにされていないよらである。そ こで本研究では阻血を生じない程度の下肢部の局所的 な与压が下肢部皮膚温および筋作業時の下肢部の筋電 位に及ぼす影響を検討した。

\section{2. 万 法}

2 -(1) 皮膚温の測定

被験者は健康な女子大学生で，表 1 に示す A，Bを 用いた。压迫部位と圧迫量及び皮膚温測定部位は以下 の通りである。

Table 1. Physical characteristics of subjects.

\begin{tabular}{|c|cccc|}
\hline Subj. & $\begin{array}{c}\text { Age } \\
(\text { yr. })\end{array}$ & $\begin{array}{c}\text { Height } \\
(\mathrm{cm})\end{array}$ & $\begin{array}{c}\text { Weight } \\
(\mathrm{kg})\end{array}$ & $\begin{array}{c}\text { BSA } \\
\left(\mathrm{m}^{2}\right)\end{array}$ \\
\hline A & 22 & 161.6 & 50.8 & 1.48 \\
B & 22 & 150.5 & 43.7 & 1.32 \\
C & 22 & 158.1 & 50.2 & 1.45 \\
\hline
\end{tabular}

Body surface area (BSA) was estimated by the equation of Fujimoto et al., (1968).

圧迫部位は前報で匤迫に対する感受性が良いことが 示された大腿下部と，我々が常日頃靴下等で压迫する 機会の多い足首上部を右足を例として選んだ。用いた 王迫布は前報で総圧迫量［単位面積当たりのE迫量 $(\mathrm{mmHg}) \times$ 圧迫幅 $(\mathrm{cm})]$ に対する王迫感が小さいこ とが示された幅 $7 \mathrm{~cm}$ のフである。この幅は下肢部 に打ける王迫部位間の 2 部位弁別丁度可知差距離に相 等しい，なお，王迫布は血圧を測定する祭に用いるカ フのような構造であるが，圧迫幅を規定するために長 さ $7 \mathrm{~cm}$ で直径 $2 \mathrm{~mm}$ の竹を $1 \mathrm{~mm}$ の間隔をあけな

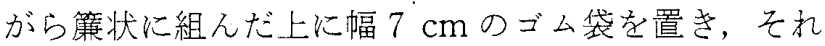
らを伸びない布（シーチング生地）で包んだものであ る。これにより皮膚に接する压迫面積を正確に与える ことができる。な拈，ゴムの上側（非皮膚接触側）と 布とは接着し王力が皮膚方向に作用するよらにした。

压迫量は前報で示されたように圧迫部に“ややきつ い”といら王迫感が生じる40mmHg と, “きつい”とい う圧迫感が生じる $80 \mathrm{mmHg}$ である。

皮膚温の測定部位は圧迫部位(右足)の近接する上と 下，压迫部位の中央に対称な非王迫側（左足）の位置, 圧迫側の右足背と非生迫側の左足背の計 5 ケ所であ る.

本実験では下肢部を露出した場合と衣服で被覆した 場合を区別し，いづれの場合も身体が温熱中性域の近 傍で快適状態にある二種の温熱環境条件(A)を設定し

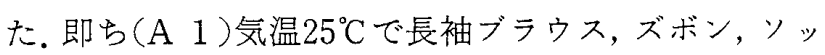
クス,ブラジャ一，パンティーを着用した場合と（A 2 )気温 $28^{\circ} \mathrm{C}$ で長袖ブラウス, ショートパンッ, ブラ ジャー，パンティーを着用した場合である。

被験者は皮膚温測定用サーミスタを装着した後，椅 座位で皮膚温の定常状態を得るために 1 時間安静にし た。そして，1時間足首上部あるいは大腿下部を圧迫 した。なお、コントロールとして非王迫時の場合も実 験した。各部位の皮膚温について $40 \mathrm{mmHg}$ 或いは80 $\mathrm{mmHg}$ 圧迫時の圧迫終了直前の值から王迫開始值前 の値を減じた値 $(\triangle T s)$ を求め，非王迫時の実験での 同時期の $\triangle T s$ と比較した。

\section{2 -(2) 筋電位の測定}

被験者は表 1 中の A 扣よびCである.医迫部位は下 腿中央部衿よび大腿下部で，皮膚温実験と同じ幅 7 $\mathrm{cm}$ の圧迫布を用い，20，40，60，或いは80mmHg の 王力で压迫した。なお，下腿中央部が王迫されると前 脛骨筋と腓腹筋が，大腿下部が王迫されると内側広筋 と外側広筋が王迫される。筋電位は内側広等, 外側広 筋, 前脛骨筋, 腓腹筋の 4 筋について筋絨維の走行方 向に平行に表面電極を貼り付け双極誘導により導出し た。ここに，電極間距離は $25 \mathrm{~mm}$ とし，電極間抵抗は $20 \mathrm{k} \Omega$ 以下とした。

作業は下肢部がズボン等により圧迫され易く下肢部 に大きな筋負担がかかる尻を落としたしゃがみ位の保 持である，この時，足首の関筋角度は前脛骨筋の活動 レベルが最大筋力 (MVC) の約 $25 \%$ となるよ5に予め 
設定した，なお，前脛骨筋の最大筋力は足首を背屈さ せて求めた。 また, 他の筋の最大筋力は以下の方法に よった。内側広筋々外側広筋は脚を前方に伸ばし膝関 節を伸展させた。腓腹筋は上方より負荷をかけ爪先立 ちをさせた。いずれも関節の近位端を固定し，遠位端 に動かない抵抗を加えた。

被験者は電極を付け，各筋の最大筋力を測定した。 そして椅座位で10分間安静にした後，9分間のしゃが 又位の姿勢を維持し, 続いて10分間の椅座位安静回復 を保った。しゃがみ位を維持している間の 2 分目から 7 分目にか村て 5 分間圧迫した(圧迫期)。従って, 初 めの 2 分間叔よび 7 分後の 2 分間は压迫しないでしゃ が位を維持していることになる。なお，7分目から 9 分目までを除圧期之呼ぶ。この 9 分間という作業時 間は被験者が姿勢を維持し得るほ泳最長の時間であっ た。なおコントロールとして 9 分間を通して非王迫 時のしゃがみ位の実験も行った。

安静時々回復時及び作業時之最大筋力測定時の EMG をペンレコーダ（日本電気三栄，8S36）に直記す ると伴にデータレコーダ（TEAC， R-71）に記録し, 実験終了後積分計(日本電気三栄, 積分ニニット1322) にかけ EMG 積分值を求めた。

各筋の筋負荷レベルを最大筋力発揮時の EMG 積分 值に対する比率 (\%MIE: Maximum Integrated $\mathrm{EMG}$ )で表した。各筋について压迫終了直前の\%MIE から圧迫開始直前の\%MIEを減じた值（圧迫期の $\triangle \%$ $\mathrm{MIE})$ 之作業終了直前の $\% \mathrm{MIE}$ から圧迫終了直前の $\%$ MIEを減じた値（徐生期の $\triangle \% \mathrm{MIE}$ ) 求めた。非圧 迫時にも同時期の $\triangle \% \mathrm{MIE}$ 求め, 各圧力での $\triangle \%$ MIEと比較した。

\section{3. 結 果}

3 -(1) 皮膚温の変化について

圧迫部位の $\triangle T S$ はその部位に近接する上下の $\triangle$ Tsが同じ変化傾向を示したので平均して求めた。

足首上部圧迫時の圧迫部位と圧迫部位対称位置の $\triangle$ Tsについて被験者数を繰り返し数とし温熱環境条件 (A), 部位 (B), 圧力 (C)を要因とする分散分析を行。 た。交互作用はなく温熱環境条件と部位は危険率 $5 \%$ で，压力は危険率 $1 \%$ で有意差があった。 そこで, 各 要因について水準毎に平均値を求め平均值間の差を検 定し，その結果を図1のCASEIに示す. $\triangle$ Ts の下降
度は温熱環境条件(A 1)の方が(A 2)上りも大きく， 圧迫部位 (B 1) より圧迫部位対称位置 (B 2)の方が大 きかった。非王迫時と比較して $40 \mathrm{mmHg}$ および 80 $\mathrm{mmHg}$ 厈迫時での $\triangle \mathrm{Ts}$ の下降度は大きかったが，40 $\mathrm{mmHg} と 80 \mathrm{mmHg}$ 圧迫時との間には有意差はなかっ た。次に同圧迫時の圧迫側の末梢である右足背と非王

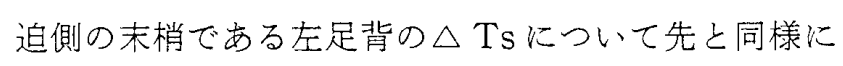
分散分析を行った。交互作用はなく温熱環境条件は危 険率 $1 \%$ で圧力は危険率 $5 \%$ で有意差があったが, 部

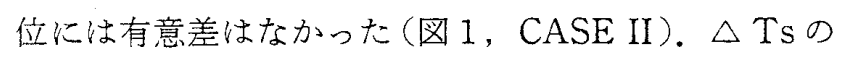
下降度は温熱環境条件(A 1)の方が(A 2)上りも大 きかった。非圧迫時と比較して $40 \mathrm{mmHg}$ 扝よび 80 $\mathrm{mmHg}$ 圧迫時での $\triangle \mathrm{Ts}$ の下降度は大きかったが，40 $\mathrm{mmHg}$ と $80 \mathrm{mmHg}$ 圧迫時との間には有意差はなかっ た。

今度は大腿下部圧迫時の圧迫部位と圧迫部位対称位 置の $\triangle T S$ S にいて先と同様に分散分析を行った，交 互作用はなく温熱環境条件が危険率 $1 \%$ で，圧力と部 位は危険率 $5 \%$ で有意差があった（図 1，CASE III）。 $\triangle T$ S の下降度は温熱環境条件(A 1)の方が(A 2)上 りも大きく, 圧迫部位 $(\mathrm{B} 1)$ 上り圧迫部位対称位置 $(\mathrm{B}$ 2 )の方が大きかった.非王迫時と比較して $40 \mathrm{mmHg}$ 和よび $80 \mathrm{mmHg}$ 圧迫時での $\triangle \mathrm{Ts}$ の下降度は大き かったが，40mmHg と $80 \mathrm{mmHg}$ 圧迫時との間には有 意差はなかった。次に同圧迫時の圧迫側の末梢である 右足背と非王迫側の末梢である左足背の $\triangle T s に つ い$ て先と同様に分散分析を行った，温熱環境条件のみが 危険率 $5 \%$ で有意差があった(図 1, CASE IV). $\triangle \mathrm{Ts}$ の下降度は温熱環境条件(A 1)の方が(A 2)上りも 大きかった。

3 -(2) 筋電位の変化について

\%MIEを 4 筋について求めたが，一般に外側広筋， 内側広筋，腓腹筋には非圧迫時を含め压迫時において ほとんど活動がなかった。 そこで非活動筋への圧迫の 影響については腓腹笳の变化から検討した。これは筋 自体が圧迫された場合（下腿中央部圧迫時）と筋の上 部が圧迫された場合（大腿下部圧迫時）とが比較可能 なためである．活動筋への圧迫の影響については前脛 骨筋の\%MIEの変化から検討した。

腓腹筋の圧迫期(表 2) と除圧期(表 3 )の $\triangle \% \mathrm{MIE}$ について压迫部位 $(\mathrm{B})$ と圧力 $(\mathrm{C})$ を要因とし被験者数 を繰り返し数とする分散分析を行った所，压迫期およ 
CASE I

A; THERMAL CONDITION
CASE II

A1; Ta: $25^{\circ} \mathrm{C}$,

$\mathrm{A} 2 ; \mathrm{Ta}: 28^{\circ} \mathrm{C}$
CASE III

Clothing : panty, brassier, socks, pants, long sleeve shirts Clothing : panty, brassier, short pants, long sleeve shirts

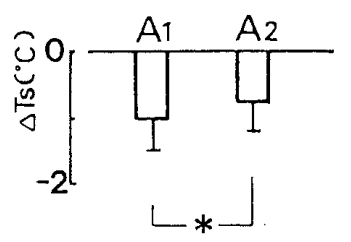
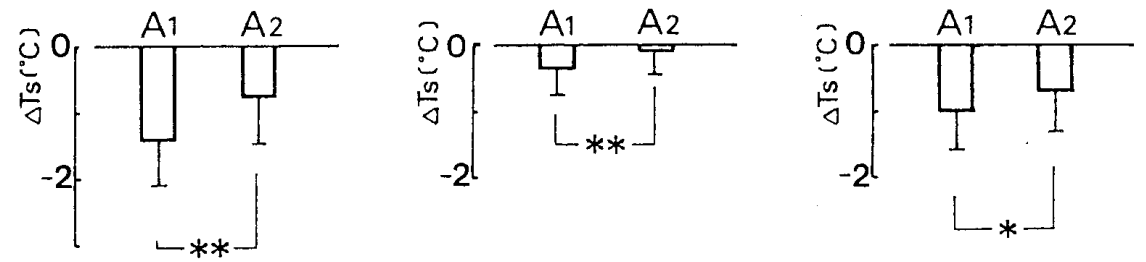

$B$; REGION $B_{1}$; pressurized region, $B_{2}$; symmetry region of $B_{1}$

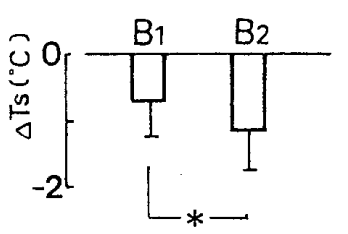

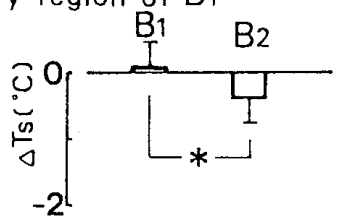

C; PRESSURE
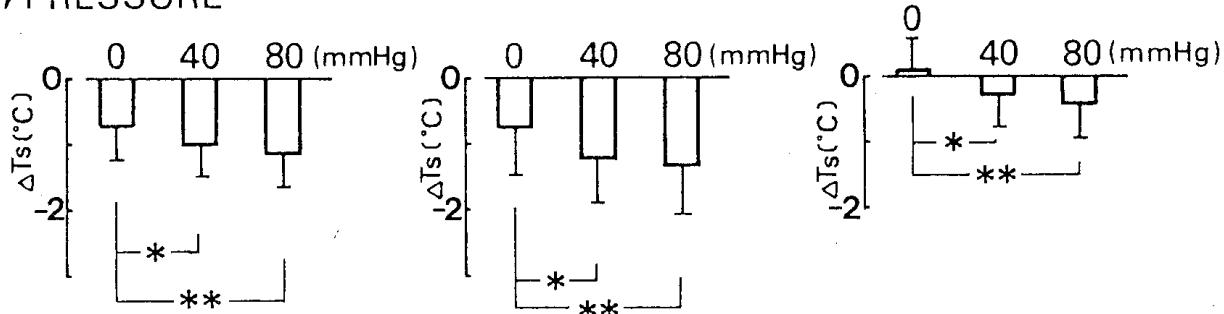

Fig. 1 Means and $95 \%$ confidence limit of $\Delta$ Ts by level in each factor. CASE I, CASEII and CASEIII, CASEIV showed $\Delta$ Ts while upper region of ankle and lower region of thigh was pressured respectively. CASE I ; $\triangle \mathrm{T}$ s of pressure region and symmetry region. CASEII ; $\triangle \mathrm{T}$ s of dorsal side of right and left foot. CASEIII ; $\Delta$ Ts of pressure region and symmetry region. CASEIV; $\Delta$ Ts of dorsal side of right and left foot. $*:<.05, * *: \mathrm{p}<.01$

び除圧期のいずれも両主要因および交互作用は有意な 値ではなかった。

次に圧迫期の前脛骨筋の $\triangle \% \mathrm{MIE}$ について先と同 様に 2 要因の分散分析を行った所，压迫部位は危険率 $5 \%$ 水準で，欧力は危険率 $1 \%$ で有意差があった（図 2 ，上段)。 $\triangle \% \mathrm{MIE}$ は外側広筋上を圧迫した場合 $(\mathrm{B}$ 2 )と比較して前脛骨筋上を压迫した場合(B 1 )の方

Table 2. Analysis of variance for $\Delta \% \mathrm{MIE}$ of gastrocnemius during pressure.

\begin{tabular}{|c|crc|}
\hline FACTOR & SS & DF & F \\
\hline B & .05 & 1 & 2.27 \\
C & .16 & 4 & 1.78 \\
B $\times$ C & .16 & 4 & 1.87 \\
E & .22 & 10 & \\
\hline TOTAL & .59 & 19 & \\
\hline
\end{tabular}

$\mathrm{B}$ : pressure region, $\mathrm{C}$ : pressure
が小さい。 また，非圧迫時と比較して $20,40,60 \mathrm{mmHg}$ 圧迫時では有意差はないが, $80 \mathrm{mmHg}$ 圧迫時では減少 した. 除圧期の前脛骨等の $\triangle \% \mathrm{MIE}$ について先と同様 に 2 要因の分散分析を行った所，圧力のみが危険率 $5 \%$ で有意差があった(図 2, 下段)。 $\triangle$ \% MIE は非圧 迫時と比較して $20,40,60 \mathrm{mmHg}$ 圧迫時には有意差は ないが，80mmHg 王迫時では增加した。

Table 3. Analysis of variance for $\triangle \% \mathrm{MIE}$ of gastrocnemius after release of pressure.

\begin{tabular}{|c|rrr|}
\hline FACTOR & \multicolumn{1}{|c|}{ SS } & DF & F \\
\hline B & 4.03 & 4 & 2.55 \\
C & .02 & 1 & .05 \\
B $\times$ C & .95 & 4 & .60 \\
E & 3.96 & 10 & \\
\hline TOTAL & 8.96 & 19 & \\
\hline
\end{tabular}

$\mathrm{B}$ : pressure region, $\mathrm{C}$ : pressure 

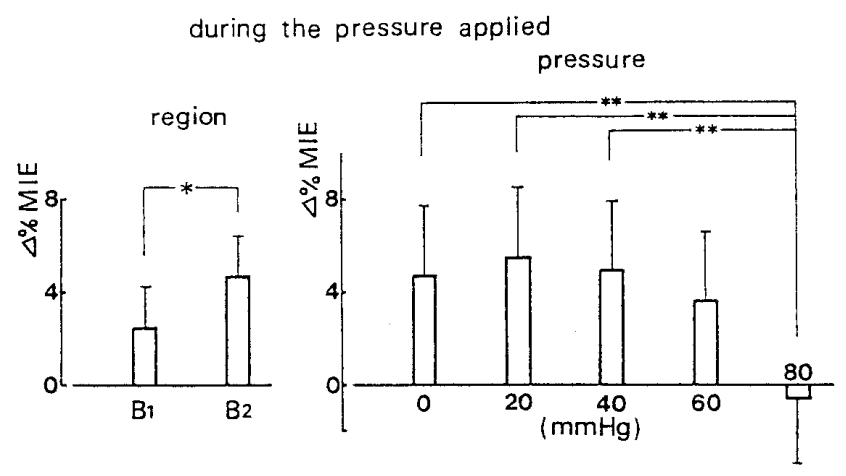

after release of pressure

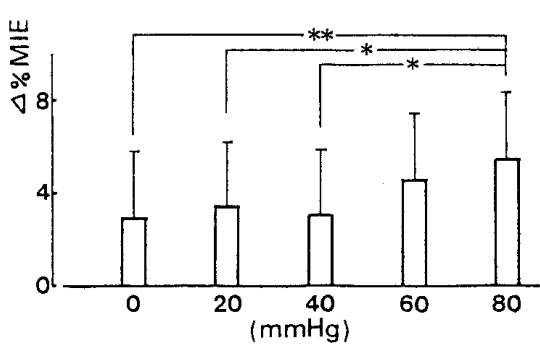

Fig. 2 Means and $95 \%$ confidence limit of $\triangle \%$ MIE of tibialis anterior by level in each factor during pressure applied (upper figure.) and after release of pressure (lower figure.). $\mathrm{B} 1$; in the case of tibialis anterior was pressured. B2; in the case of vastus lateralis was pressured. * ; $\mathrm{p}<.05 . * * ; \mathrm{p}<.01$

\section{4. 考察}

4 一(1) 皮膚温の変化について

温熱環境条件(A 1) 拈よび(A 2) に执いて被験者 はいずれも心理的に快適な状態であったが，皮膚温の 下降度は温熱環境条件の（A 1)の方が(A 2)より大 きかった，即方気温が低いと，下肢が被覆されても皮 膚温の下降度情大さいことが示された。

大腿下部圧迫時の左右の足背の皮顱温 (CASE IV) を除いて，他の皮膚温は $40 \mathrm{mmHg}$ 或いは80mmHg で 生迫すると一様に下降した。しかしながら，皮膚温の 下降度には $40 \mathrm{mmHg}$ 压迫時と $80 \mathrm{mmHg}$ 圧迫時とで差 がなく,かつ足首上部王迫時でも大腿下部王迫時でも， 圧迫側の足背の皮膚温の下降度と非王迫側の足背の皮 膚温の下降度との間に差はなかった，従って，本研究 における皮膚温の下降は単なる圧迫部位下での血流障 害といら物理的作用に基づくといよりはむしろ他の 生理的作用に基づくのではないかと思われた。 その生 理的作用の一つとして以下のことが考えられた，皮膚 温の部位差は圧迫部位と王迫部位対称位置との間でみ

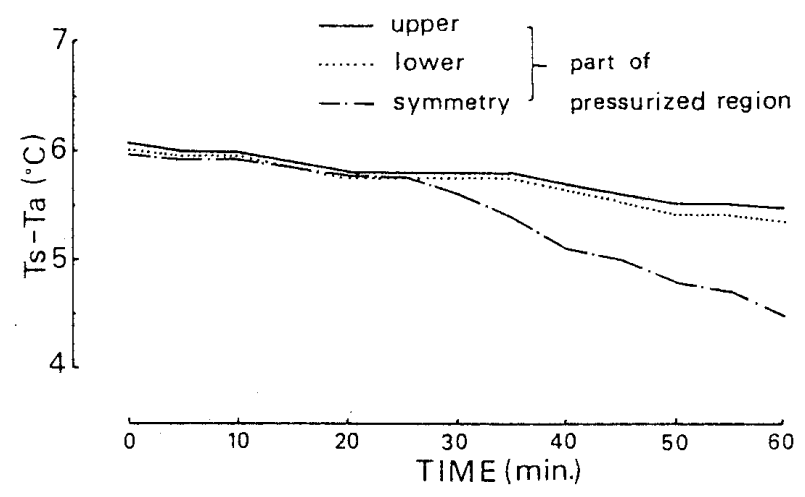

Fig. 3 Time course of $\Delta \mathrm{T}$ s (upper and lower part of pressurized region, symmetry region) in subject (A) during $80 \mathrm{mmHg}$ of pressure putted on the upper region of ankle in the thermal condition A1.

られ，足首上部珐迫時でも大腿下部圧迫時でも非圧迫 側の王迫部位対称位置の皮膚温が圧迫部位より低かっ た。図 3 に実験データの一例 (subj. A, 温熱環境条件 $\mathrm{Al}$, 王力 $80 \mathrm{mmHg}$ )を示す。圷迫開始後約 10 分目から 圧迫部位の上下，圧迫部位対称位置の皮膚温が下降し 始めるが，医迫部位対称位置の皮膚温が25分目から急 に下降するのに対し，圧迫部位の皮膚温は25分目以降 わずかに下降した，従って，王迫部位と圧迫部位対称 位置との間の皮膚温に差があったのは圧迫部位の皮膚 温の下降が王刺激により抑制されたためと推察され る。高木（1951）は王反射の一例として皮膚王迫によ り皮膚温は全体として低下傾向にあり，大多数におい て圧迫側の皮膚温は下降度が小さく，非王迫側の下降 度が大きいことを示した。本研究とは圧迫部位や圧力 など実験手法がかなり異なるが，皮膚温が全体的に低 下することや，王迫部位と圧迫部位対称位置との間の 皮膚温の変化は高木の結果と似ており, 本研究に沶い ても圧反射が生じた可能性がある.

なお，下肢部を $40 \mathrm{mmHg}$ で王迫するヒトは怕感と してややきついと感じることから(綿貫と三平, 1986), ズボン等を着用した時にややきついと感じるようであ れば下肢部の皮膚温が低下することが考えられる。

4 一(2) 筋電位の変化について

圧迫期の前鲻骨筇の\%MIEの増加度は外側広筋上 を王迫するよりも前脛骨筋自体を王迫した方が小さ かった，従って，压迫の筋電位への影響は筋自体を匠 迫した場合に生じると考えられる。しかしながら，非 活動筋の腓腹筋への王迫の影響は筋自体を王迫しても 
大腿下部を压迫してもみられなかった。即ち, 筋自体 を王迫しても25\%MVC程度の活動をする筋を王迫した 場合にのみ筋電位の減少が生じると考えられる。また， その減少は圧迫量が $60 \mathrm{mmHg}$ 以下では見られず，80 $\mathrm{mmHg}$ に沶いてのみ見られた。一般に，筇負担が増す 之筋電位は增加するが, 作業胘を $80 \mathrm{mmHg}$ で圧迫すれ ば同一仕事量に対して少ない筋活動で済む訳であるか ら一見作業効率が良くなった様に思わ机，ゲートル等 を下腿部に巻く一つの利点が説明される。しかしなが ら, 除圧期では, 非圧迫時と比較して圧迫量が60 $\mathrm{mmHg}$ 以下では\% $\mathrm{MIE}$ の増減に変化は見られなかっ たのに対し， $80 \mathrm{mmHg}$ で圧迫すると増加した。即ち， この増加は同一仕事量に対して筋負担が大きいことを 意味するのではないかと思われる，従って，活動筋を 死迫することは結果として筋負担を増す可能性がある ことが示唆される。なお，非活動筋である腓腹筋では 非圧迫時と比較して压迫期と同様に除王期でも\% MIEの増減に差は見られなかった。 また，下肢部が 80 mmHg で圧迫されると“きつい”という圧迫感が生じ ることから（綿貫と三平，1986）ズボン等の着用によ り“きつい”という过迫感が生じる部位の筋はその活 動畫が大きい場合に圧迫により筋負担が増す可能性が あると考觉られる。

\section{5.むすび}

皮膚温の実験結果から片方の下肢を圧迫すると両方 の下肢の皮膚温は低下したが，その低下度に圧力差は なかった。 また，低下度の部位差は左右の足背間には ないが，圧迫部位と圧迫部位対称位置との間にみられ， 低下度は圧迫部位の方が小さかった。圧迫による皮膚 温の低下理由の一つとして高木らのいら圧反射が考光 られた。

筋電位の実験結果より筋が非活動状態であれば圧迫 しても筋電位に何ら変化は見られないが, 約 $25 \% \mathrm{MVC}$ の作業を行う筋自体を $80 \mathrm{mmHg}$ で圧迫すると筋電位 は減少し，一見作業効率が良くなる様に思われた。し かしながら，除圧するとそれは非压迫時と比較して逆 に増加することから，正迫が筋負担を増す可能性があ ることが示唆された。
謝辞

稿を終えるにあたり終始懇切な御助言を賜りました 大阪市立大学 生活科学部 助教授の花田嘉代子先生 に深謝致します。

\section{文 献}

藤本薰喜, 渡辺猛, 坂本淳, 湯川幸一, 森本和枝, 1968： 日本人の体表面積に関する研究。第18篇三期にまと めた算出式. 日衛誌，23(5)：7-1414.

Humphreys, P. W. and Lind, A. R., 1963: The blood flow through active and inactive muscles of the forearm during sustaind hand-grip contraction. J. Physiol., 166: 120-135.

Magora, A., Blank, A. and Gonen, B., 1980 : Effects of artificially induced ischemia (AII) on the electrophysiological pattern of muscular fatigue in healthy humans. Electromyogr. clin. Neurophysiol., $20: 125-140$.

大野静枝, 田中正敏, 1974 : ファンデーションの着衣 条件が身体生理に及汸す影響について，家政学雑誌， 25(6) : 486-490.

高木健太郎，1951：皮膚王-自律神経反射。最新医学, $9(5): 69-84$.

綿貫茂喜, 三平和雄, 1986 ：下肢部与圧時の心理的特 性の変化について, 生理人類誌. 5(1): 13-17.

（1986年 9 月 9 日受付） 